\title{
Áreas com queda da cobertura vacinal para BCG, poliomielite e tríplice viral no Brasil (2006-2016): mapas da heterogeneidade regional
}

\author{
Areas with declining vaccination coverage \\ for BCG, poliomyelitis, and MMR in Brazil \\ (2006-2016): maps of regional heterogeneity \\ Áreas con una caída de la cobertura de \\ vacunación para BCG, poliomielitis y triple \\ vírica en Brasil (2006-2016): mapas de la \\ heterogeneidad regional
}

Luiz Henrique Arroyo

Antônio Carlos Vieira Ramos 1

Mellina Yamamura 1

Teresinha Heck Weiller 1

Juliane de Almeida Crispim 1

Denisse Cartagena-Ramos 1

Miguel Fuentealba-Torres 1

Danielle Talita dos Santos 1

Pedro Fredemir Palha 1

Ricardo Alexandre Arcêncio 1

\section{Resumo}

A imunização é reconhecida como uma das intervenções mais bem-sucedidas e custo-efetivas, resultando na erradicação e no controle de diversas doenças em todo o mundo. Todavia, uma preocupante redução na cobertura vacinal tem sido observada no Brasil, trazendo o recrudescimento de algumas doenças até então superadas. Dessa forma, no intuito de realizar um diagnóstico situacional que pondere as diferentes regiões do país e a tendência temporal de cobertura vacinal, o presente estudo teve o objetivo de evidenciar áreas com queda da cobertura vacinal de BCG, poliomielite e tríplice viral no Brasil por meio de um estudo ecológico que coletou informações acerca do número crianças de até um ano de idade imunizadas para essas três vacinas, no período entre 2006 e 2016, por município brasileiro. Os dados foram adquiridos por meio do Departamento de Informática do SUS. Foi realizada uma varredura espacial, analisando as variações espaciais nas tendências temporais de cobertura vacinal. Foi observada uma tendência de redução no número de imunizações no Brasil, com quedas de 0,9\%, 1,3\% e 2,7\% ao ano para BCG, poliomielite e tríplice viral, respectivamente. Ademais, aglomerados significativos com tendências temporais de redução da cobertura vacinal foram verificados em todas as cinco regiões brasileiras. O estudo evidencia uma importante redução na cobertura vacinal nos últimos anos, constatando heterogeneidades consideráveis entre os municípios. Dessa forma, uma atenção singular e planejamento estratégico condizente com as características de cada localidade são necessários para o controle tanto da redução de cobertura vacinal como do reaparecimento de doenças no Brasil.

Cobertura Vacinal; Imunização; Análise Espacial

\section{Correspondência}

L. H. Arroyo

Escola de Enfermagem de Ribeirão Preto, Universidade de São Paulo.

Av. dos Bandeirantes 3900, Campus Universitário, Ribeirão Preto, SP 14040-902, Brasil.

luiz.arroyo@hotmail.com

1 Escola de Enfermagem de Ribeirão Preto, Universidade de São Paulo, Ribeirão Preto, Brasil. 


\section{Introdução}

A imunização é a intervenção custo-efetiva mais relevante para o controle global de doenças infectocontagiosas 1 , salvando inúmeras vidas, reduzindo a mortalidade e a incidência mundial de doenças preveníveis 2. A Assembleia Mundial da Saúde propôs o Plano de Ação Global para Vacinas 2011 2020, cujo objetivo é garantir a universalidade da imunização e a melhora dos indicadores mundiais de saúde por meio da ampliação da cobertura vacinal, independentemente da região do mundo 3 .

A Organização Mundial da Saúde (OMS) reportou, em 2017, que a região das Américas apresentou o maior número de registros de crianças imunizadas em todo o mundo, alcançando aproximadamente 116 milhões de imunizações. Entretanto, no Brasil, o Sistema Nacional de Vigilância do Programa Nacional de Imunizações (PNI) identificou uma preocupante diminuição da cobertura vacinal na última década, sendo esse o caso das vacinas do Bacilo Calmette-Guérin (BCG), poliomielite e tríplice viral 4,5 .

De acordo com o Calendário Nacional de Vacinação, a BCG, que previne as formas mais graves de tuberculose, deve ser administrada no nascimento da criança em uma única dose. No caso da poliomielite, são aplicadas três doses aos dois, quatro e seis meses de vida. A vacina tríplice viral, que previne a ocorrência do sarampo, caxumba e rubéola, deve ser administrada aos 12 meses de vida da criança 6.

A situação reportada despertou grande preocupação por parte das autoridades sanitárias brasileiras, haja vista a possibilidade do recrudescimento de algumas doenças até então superadas ou controladas. Segundo os registros do próprio PNI, o declínio da imunização é caracterizado como heterogêneo entre os municípios brasileiros e pode ser reconhecido com um fenômeno de desigualdade, conforme pesquisa conduzida nacionalmente. Todavia, isso não é um fenômeno isolado do Brasil, estudo realizado nos Estados Unidos evidenciou, em níveis subnacionais, o quanto a redução da cobertura vacinal tem sido significativa e desigual entre as populações com maior poder aquisitivo. Além disso, algumas áreas de risco para a redução da cobertura vacinal apresentaram o aparecimento de doenças imunopreveníveis, como sarampo e coqueluche 7.

De acordo com o PNI, os determinantes da cobertura vacinal estão relacionados com a percepção enganosa dos cuidadores de que não é preciso mais vacinar, haja vista o pensamento de que as doenças desapareceram, com a desinformação sobre as vacinas e a falta de acompanhamento dos serviços de saúde da população a ser vacinada 7,8 .

Por meio de uma revisão da literatura, observam-se poucos estudos que se utilizam de recursos cartográficos para evidenciar as coberturas vacinais em níveis subnacionais, ou regionais, como no caso dos municípios. Dentre alguns desses estudos, destaca-se o de Barata et al. 8, que trouxe aspectos relevantes e críticos quanto aos determinantes da cobertura vacinal nas capitais brasileiras, no entanto, supõem-se que, nas regiões interioranas, ou seja, em pequenos municípios, a situação de cobertura seja ainda mais crítica e emergencial.

Para adoção de medidas imediatas de saúde pública, é importante um diagnóstico situacional com certa amplitude, em que, além da detecção das áreas de queda de cobertura, por meio das variações espaciais, considerem-se também os elementos temporais desse fenômeno. Por assim dizer, mais do que cartografar os gradientes de vacinação, é importante diagnosticar o ritmo de elevação e ou redução de cobertura de uma área no decorrer do tempo.

Um dos métodos que pode responder a essa exigência é a técnica de análise de variações espaciais nas tendências temporais (VETT), que tem sua aplicabilidade na saúde pública ainda restrita, o que confere uma importante originalidade ao presente estudo, principalmente perante a temática de cobertura vacinal. Dessa forma, o objetivo da investigação foi evidenciar áreas com queda da cobertura vacinal de BCG, poliomielite e tríplice viral no Brasil. 


\section{Métodos}

Foi realizado um estudo ecológico nos 5.570 municípios brasileiros, tendo, como população, o número de crianças de até um ano de idade (12 meses) vacinadas anualmente para BCG, poliomielite e tríplice viral, no período de 2006 a 2016.

Para a coleta de dados, foi utilizado o Sistema de Avaliação do Programa de Imunizações (SAPI), gerido pela Coordenação Geral do PNI e disponibilizado livremente pelo Departamento de Informática do SUS (DATASUS). Por meio do Boletim Diário de Doses Aplicadas de Vacinas, formulado pelas Secretarias Municipais de Saúde, são disponibilizadas as informações de cobertura da imunização para os imunobiológicos de interesse do estudo. O cálculo da cobertura é realizado pela fórmula:

$$
\text { Cobertura }=\frac{n^{\text {o }} \text { de crianças vacinadas considerando esquema completo da vacina }}{\text { população alvo da vacina }} \times 100
$$

Considerando o calendário vacinal nacional disponível, a criança foi considerada para o cálculo da cobertura apenas quando recebe todas as doses recomendadas para o esquema completo da vacina, ou seja, para a BCG e tríplice viral, são consideradas as primeiras doses, enquanto, para a poliomielite, apenas depois da tomada da terceira dose. De acordo com o período de imunização preconizado pelo PNI, todas as vacinas têm como população-alvo crianças com até um ano de idade 6 .

Importante frisar que a cobertura vacinal disponibilizada pelo SAPI apresenta limitações já apontadas por outros autores, podendo sub ou superestimar seus valores, exatamente pela dificuldade de verificar-se a completude dos esquemas vacinais nas crianças. Ademais, a identificação da população-alvo, para a qual é utilizado como base o Sistema de Informações sobre Nascidos Vivos (SINASC), também pode conter imprecisões, dada a falta de ponderação das variações de fecundidade, fluxos migratórios e de registros incompletos, que podem não refletir a real taxa de natalidade no país 9,10.

No objetivo de identificar as VETT de vacinação, foi utilizada a estatística de varredura espacial desenvolvida por Kulldorff 11. Diferentemente das análises de varredura estritamente espaciais ou espaçotemporais, a VETT é usada para detectar e inferir regiões geográficas excepcionalmente diferentes em relação a sua tendência temporal.

O método utiliza o período de forma fixa, que, nesse caso, foi considerado a unidade ano, e gradualmente vasculha, por meio de janelas espaciais de diferentes tamanhos, a tendência temporal dentro e fora de cada uma dessas. Após a identificação de janelas espaciais com diferenças de tendência temporal, é realizado um teste de hipótese, sendo a hipótese nula $\left(\mathrm{H}_{0}\right)$ : não existem diferenças entre as tendências temporais dentro e fora das janelas espaciais; e hipótese alternativa $\left(\mathrm{H}_{1}\right)$ : as tendências temporais são diferentes dentro e fora das janelas espaciais.

A análise VETT é realizada por uma tendência temporal linear a partir de uma distribuição de Poisson:

$$
Y_{i j} \sim P_{0}\left(E_{i j} \times \theta_{i j}\right)
$$

Na qual, $Y_{i j}$ e $E_{i j}$ são, respectivamente, o número observado e esperado de casos ou eventos em uma determinada área $i$ e um período $j$. Para o modelo em questão, o número esperado de casos em cada área é calculado usando a padronização indireta:

$$
E_{c}=p \times \frac{C}{P}
$$

Em que $E_{c}$ é o número de casos esperados dentro da janela sob a $\mathrm{H}_{0} ; p$, a população no local de interesse; $C$ e $P$ são o número total de casos e habitantes, respectivamente. Além disso, $\theta_{i j}$ é o risco relativo na área $i$ e no período $j$. Assim, são considerados como componentes para o $\log \left(\theta_{i j}\right)$ :

$$
\log \left(\theta_{i j}\right)=\alpha_{0}+A_{i}+B_{j}+C_{i j}
$$

Em que $\alpha_{0}$ é o intercepto (taxa geral), $A_{i}$ representa o componente espacial; $B_{j}$, o temporal; e $C_{i j}$, a interação espaçotemporal 12. Nesse caso, esses componentes podem ser definidos como: $A_{i}=\phi_{i}, B_{j}=\beta_{t j}$, e $C_{i j}=\delta_{i t j}$ em que $\phi_{i}$ é um efeito aleatório da área; $\beta_{t j}$ é um termo de tendência linear no tempo $t_{j} ; \delta_{i}$, um 
efeito aleatório de interação entre a área $(i)$ e o tempo $\left(t_{j}\right){ }^{12}$. A tendência temporal foi estimada usando a regressão de Poisson, considerando o tempo como variável independente. A partir da contagem de casos e eventos esperados, é realizado um cálculo de verossimilhança e a máxima verossimilhança sobre todas as janelas possíveis de análise. Essa máxima é comparada com a de um grande conjunto de dados aleatórios derivados de uma simulação de Monte Carlo, possibilitando a inferência estatística nas análises 13 .

É importante destacar que os aglomerados identificados nessas análises não indicam que o número de crianças imunizadas é alto ou baixo em relação ao restante do país, mas identifica unicamente sua tendência temporal em comparação ao restante do território nacional 13,14.

Por estarem disponíveis apenas dados de cobertura vacinal no SAPI e considerando que, para as referidas análises, é necessária a contagem de crianças imunizadas por município brasileiro, dado o uso do modelo de Poisson, foi coletado também o valor correspondente à população-alvo das vacinas. Conforme citado anteriormente, esse dado é disponibilizado também, de forma livre, por meio do SINASC. A partir da fórmula de cobertura citada acima, foi calculado o número de crianças vacinadas com esquema completo preconizado pelo PNI por município brasileiro, não sendo utilizado, para as análises de VETT, o número de doses que essas receberam.

Foram especificados como parâmetros da análise de VETT: tamanho máximo de janela espacial da área de risco de 50\% da população do estudo; formato circular da janela espacial; máximo de 999 replicações na simulação de Monte Carlo; e não existir sobreposição geográfica para reportar aglomerados hierárquicos. A escolha do tamanho máximo do aglomerado geográfico para 50\% da população é recomendação usual para esse tipo de análise, sendo que o software SatScan 9.6 (http: \lwww. satscan.org), no qual foram realizadas essas análises, mantém o estudo numa escala regional 1 . O erro tipo I foi fixado em $5 \%$ como estatisticamente significativo $(\mathrm{p}<0,05)$.

Por meio dos resultados da análise de VETT, foram construídos mapas temáticos dos municípios brasileiros identificando os aglomerados significativos para a referida análise, juntamente com gráficos contendo informações de coberturas vacinais dessas mesmas áreas no decorrer dos anos. Ademais, a análise de varredura empregada possibilitou a identificação das tendências temporais locais de cada um dos municípios pertencentes a esses aglomerados. Essa informação foi utilizada para a elaboração de histogramas de distribuição de frequência dessas tendências temporais locais. Os mapas foram realizados no software ArcGis 10.6 (http://www.esri.com/software/arcgis/index.html), enquanto os gráficos e histogramas foram desenvolvidos pelo software R (http://www.r-project.org) e pacote ggplot 2 .

O presente estudo utiliza-se de dados de domínio público de acesso irrestrito, para o qual não existe identificação dos indivíduos participantes da investigação, dessa forma, não sendo necessária apreciação por parte de Comitê de Ética em Pesquisa.

\section{Resultados}

Observou-se cobertura vacinal média da BCG, poliomielite e tríplice viral de 90,6\%, 107\% e 102,3\%, respectivamente, entre os anos de 2006 e 2016. Nos casos da BCG e da poliomielite, o ano de 2016 demonstrou os menores valores da cobertura no período analisado, obtendo 81,1\% (BCG) e 91\% (poliomielite) da população-alvo imunizada. Em relação à tríplice viral, 2013 foi o ano com menor cobertura, em que $77,1 \%$ das crianças com até um ano de idade foram vacinadas no país.

Nacionalmente, observou-se uma tendência de redução no número de imunizações no Brasil no decorrer dos anos para as três vacinas. No caso da BCG, a tendência foi de redução das imunizações na ordem de 0,9\% ao ano. Para a poliomielite, esse valor alcançou 1,3\% de crianças vacinadas anualmente. A tríplice viral externou o maior valor de redução no número de vacinados, chegando a encolher $2,7 \%$ a cada ano.

As análises de VETT para o número de crianças imunizadas em relação a BCG, poliomielite e tríplice viral são apresentadas, respectivamente, nas Figuras 1, 2 e 3, juntamente com a cobertura vacinal no decorrer dos anos para esses aglomerados significativos. Da análise, foram identificados seis aglomerados para BCG, cinco para poliomielite e quatro para tríplice viral. Os aglomerados englobaram 


\section{Figura 1}

Aglomerados significativos para análise de variações espaciais nas tendências temporais da vacina BCG e suas coberturas vacinais anuais. Brasil, 2006-2016.

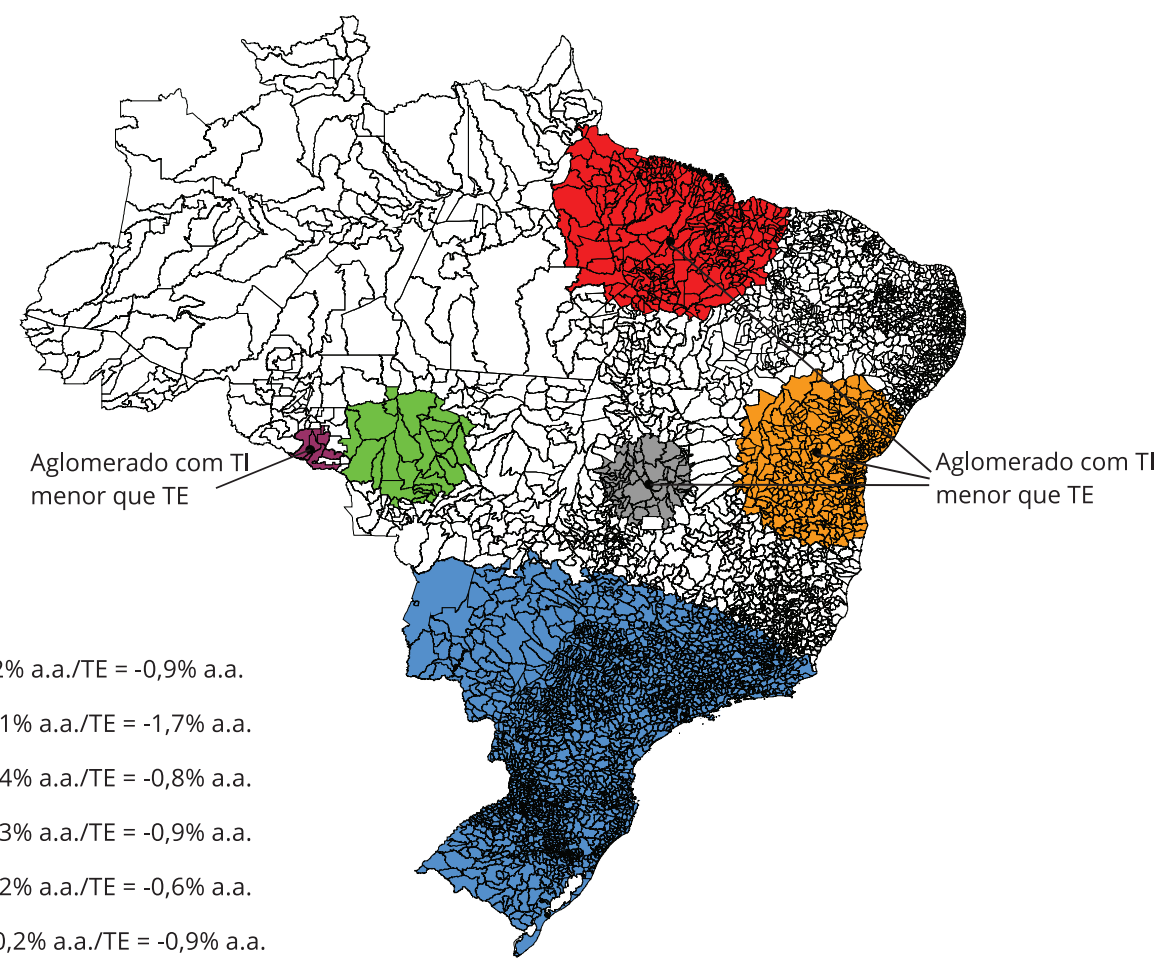

Aglomerados

$1-\mathrm{Tl}=2,2 \%$ a.a. $/ \mathrm{TE}=-0,9 \%$ a.a.

$2-\mathrm{Tl}=-0,1 \%$ a.a. $/ \mathrm{TE}=-1,7 \%$ a.a

$3-\mathrm{TI}=-2,4 \%$ a.a. $/ \mathrm{TE}=-0,8 \%$ a.a.

$4-\mathrm{TI}=-3,3 \%$ a.a. $/ \mathrm{TE}=-0,9 \%$ a.a.

$5-\mathrm{TI}=-4,2 \%$ a.a. $/ \mathrm{TE}=-0,6 \%$ a.a.

$6-\mathrm{TI}=-10,2 \%$ a.a. $/ \mathrm{TE}=-0,9 \%$ a.a.

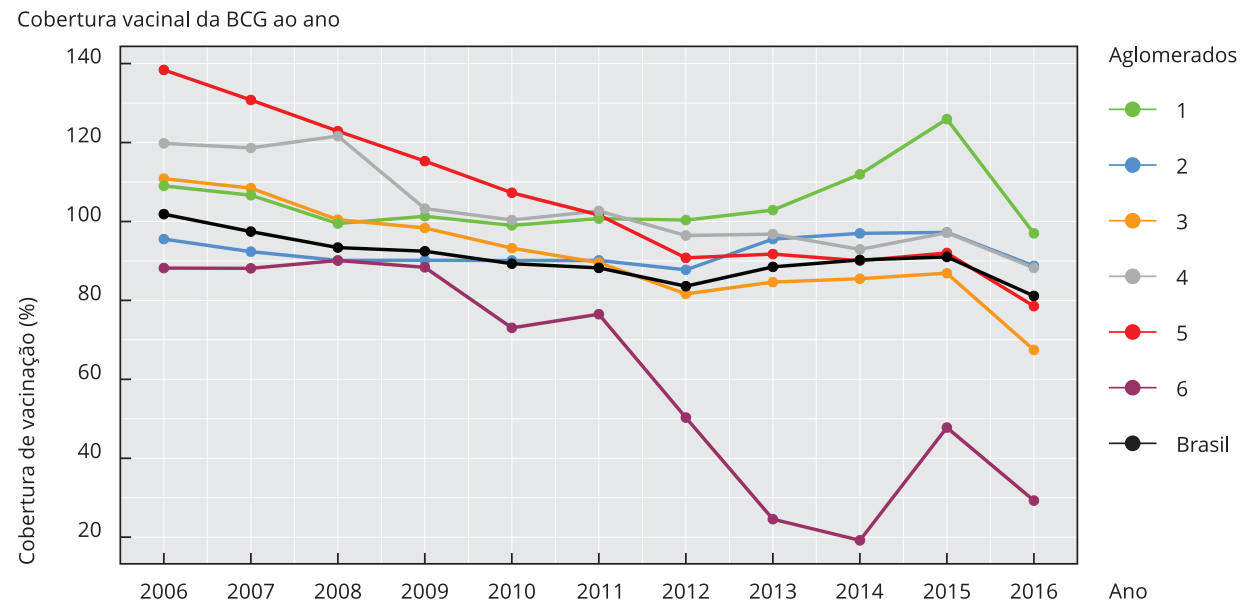

a.a.: ao ano; TE: tendência temporal externa; TI: tendência temporal interna. 


\section{Figura 2}

Aglomerados significativos para análise de variações espaciais nas tendências temporais da vacina poliomielite e suas coberturas vacinais anuais. Brasil, 2006-2016.
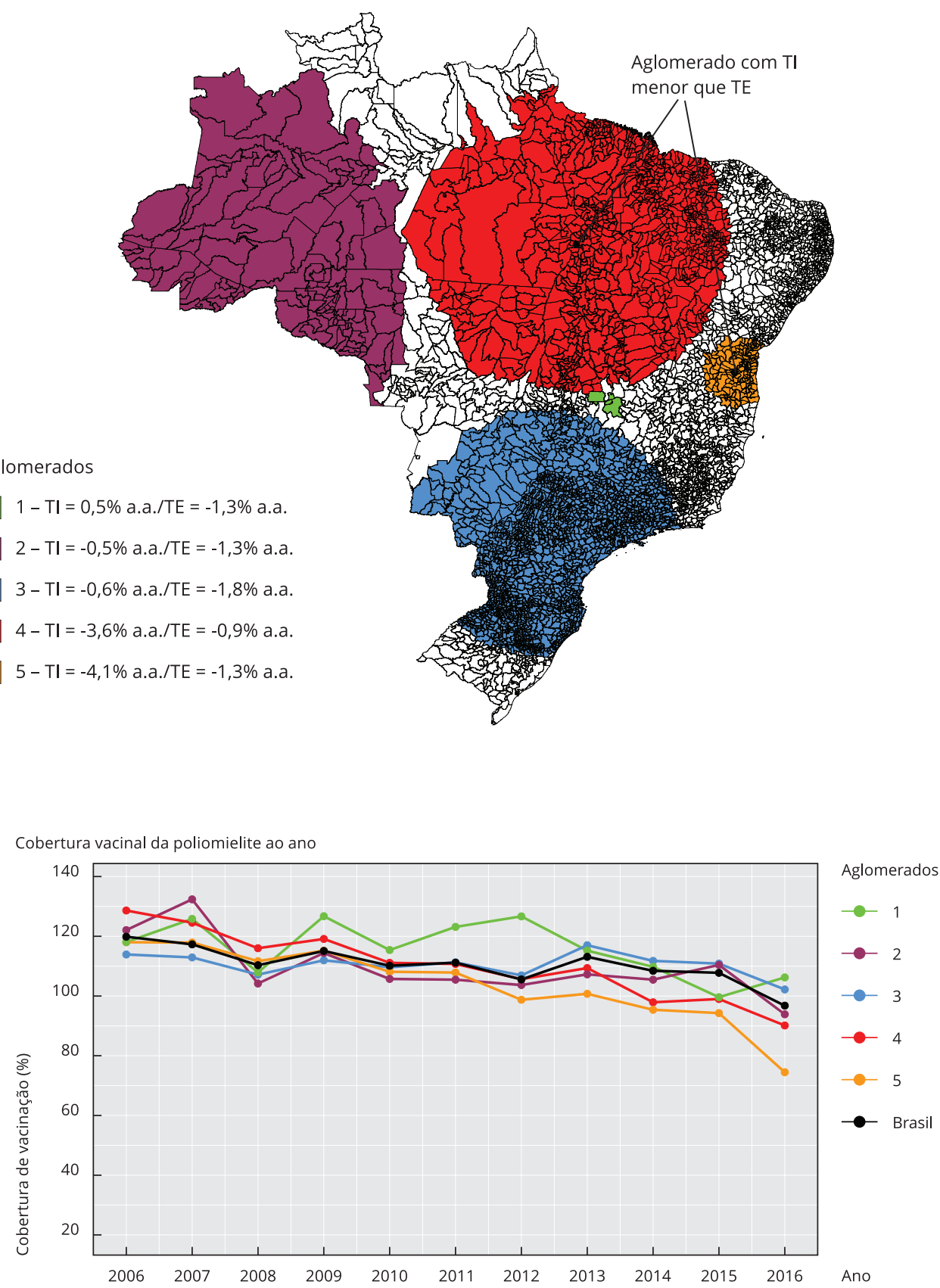

a.a.: ao ano; TE: tendência temporal externa; TI: tendência temporal interna. 


\section{Figura 3}

Aglomerados significativos para análise de variações espaciais nas tendências temporais da vacina tríplice viral e suas coberturas vacinais anuais. Brasil, 2006-2016.
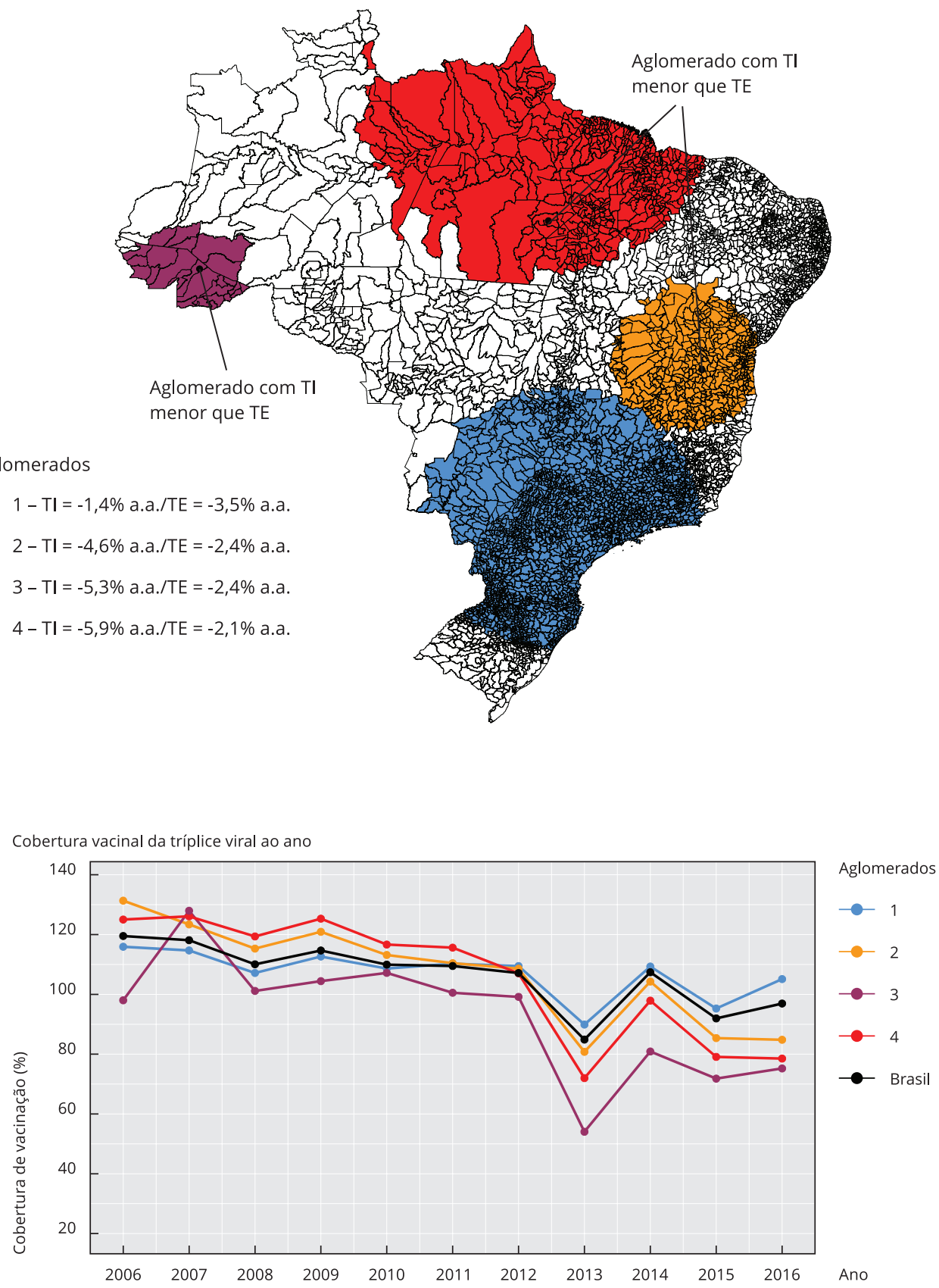

a.a.: ao ano; TE: tendência temporal externa; TI: tendência temporal interna. 
todos os agrupamentos de Unidades da Federação, ou seja, as cinco divisões regionais do Brasil, sendo que cada uma apresentou distintas tendências temporais e dimensões territoriais.

Essas áreas podem ser interpretadas a partir de sua tendência temporal interna (TI) e externa (TE). As TI representam o grau de crescimento ou redução de vacinações no decorrer dos anos dentro do aglomerado, sendo essa comparada com a TE, ou seja, a tendência em todo o território nacional não pertencente a esse mesmo aglomerado. Foi possível verificar que, dentre os 15 aglomerados significativos nas análises, nove apresentaram TI de redução no número de crianças vacinadas mais intenso que as TE, expressando maior redução no número de vacinados a níveis subnacionais, comparando -os ao restante do território brasileiro. Considerando essa interpretação, as Figuras 1, 2 e 3 destacam ainda os aglomerados significativos que apresentaram essas TI menores que as TE. Outrossim, apenas duas áreas apresentaram TI positivas, sendo uma para a vacina BCG, em Mato Grosso, e outra para a poliomielite, localizada no Distrito Federal e alguns municípios de Minas Gerais. Apesar da Região Sul, Sudeste e alguns estados do Centro-oeste apresentarem TI negativas, essas foram menores que as TE, significando que, apesar das reduções, essas se apresentaram de forma mais branda que o restante do país.

Em relação às coberturas vacinais nos aglomerados significativos para as três vacinas no período analisado, foi possível identificar que a vacina BCG apresentou maiores amplitudes de cobertura entre os aglomerados, a ponto de serem observados valores de apenas $20 \%$ da população-alvo imunizada, enquanto outras localidades alcançaram mais de 100\% de cobertura.

A poliomielite variou sua cobertura entre aproximadamente $130 \%$ e $60 \%$ da população-alvo imunizada nos aglomerados, enquanto a tríplice viral variou entre $130 \%$ e $40 \%$ nos dez anos de investigação.

Na Tabela 1, são apresentadas as características dos aglomerados identificados na análise de varredura com VETT, em que são descritos os números de municípios pertencentes a cada uma dessas áreas, seus valores de significância estatística e os estados que compõem esses agregados espaciais. Os valores de significância representam que, para esses aglomerados, existe distinção com o restante do país, no que concernem às tendências temporais no número de crianças vacinadas ao ano.

Tabela 1

Características dos aglomerados significativos identificados na análise de varredura para as vacinas BCG, poliomielite e tríplice viral. Brasil, $2006-2016$.

\begin{tabular}{|c|c|c|c|c|c|}
\hline Vacina & Aglomerado & Municípios & Valor de $p$ & $\begin{array}{c}\text { População-alvo } \\
\text { vacinada ao } \\
\text { ano/100.000 mil * }\end{array}$ & Unidades da Federação \\
\hline \multirow[t]{6}{*}{$\mathrm{BCG}$} & 1 & 31 & 0,001 & 111.797 & Mato Grosso \\
\hline & 2 & 2.387 & 0,001 & 104.490 & $\begin{array}{l}\text { Rio Grande do Sul, Santa Catarina, Paraná, São Paulo, } \\
\text { Mato Grosso do Sul, Rio de Janeiro e Minas Gerais }\end{array}$ \\
\hline & 3 & 423 & 0,001 & 105.584 & Bahia \\
\hline & 4 & 59 & 0,001 & 116.983 & Goiás e Tocantins \\
\hline & 5 & 334 & 0,001 & 120.695 & Pará, Maranhão e Tocantins \\
\hline & 6 & 7 & 0,001 & 70.545 & Rondônia \\
\hline \multirow[t]{5}{*}{ Poliomielite } & 1 & 5 & 0,001 & 99.808 & Distrito Federal e Minas Gerais \\
\hline & 2 & 132 & 0,001 & 96.218 & Mato Grosso, Rondônia, Amazonas e Acre \\
\hline & 3 & 2.241 & 0,001 & 99.241 & $\begin{array}{l}\text { Rio Grande do Sul, Santa Catarina, Paraná, São Paulo, Mato } \\
\text { Grosso do Sul, Rio de Janeiro, Minas Gerais e Goiás }\end{array}$ \\
\hline & 4 & 894 & 0,001 & 99.721 & Goiás, Tocantins, Maranhão, Piauí, Bahia, Mato Grosso e Pará \\
\hline & 5 & 150 & 0,001 & 94.432 & Bahia \\
\hline \multirow[t]{4}{*}{ Tríplice viral } & 1 & 2.509 & 0,001 & 95.470 & $\begin{array}{l}\text { Rio Grande do Sul, Santa Catarina, Paraná, São Paulo, Mato } \\
\text { Grosso do Sul, Rio de Janeiro, Minas Gerais e Goiás }\end{array}$ \\
\hline & 2 & 452 & 0,001 & 97.532 & Minas Gerais e Bahia \\
\hline & 3 & 25 & 0,001 & 85.182 & Acre e Amazonas \\
\hline & 4 & 463 & 0,001 & 95.911 & Pará, Amapá e Maranhão \\
\hline
\end{tabular}

* Considerando como população apenas crianças com até um ano de idade. 
Nas Figura 4, 5 e 6 são exibidos os histogramas das tendências temporais locais dos municípios de cada um dos aglomerados. Essa demonstra a distribuição da frequência, ou número de municípios por intervalos de tendências temporais, sendo que os intervalos negativos foram representados na cor vermelha, e os positivos, na cor azul. Observou-se que tanto BCG como poliomielite e tríplice viral tiveram uma maior quantidade de municípios com tendências temporais locais negativas, sendo que, em média, a queda esteve na faixa de 1 a $10 \%$ ao ano.

\section{Figura 4}

Tendência temporal local das coberturas vacinais dos municípios pertencentes aos aglomerados significativos da análise de varredura da BCG. Brasil, 2006-2016.

4a) Aglomerado 1

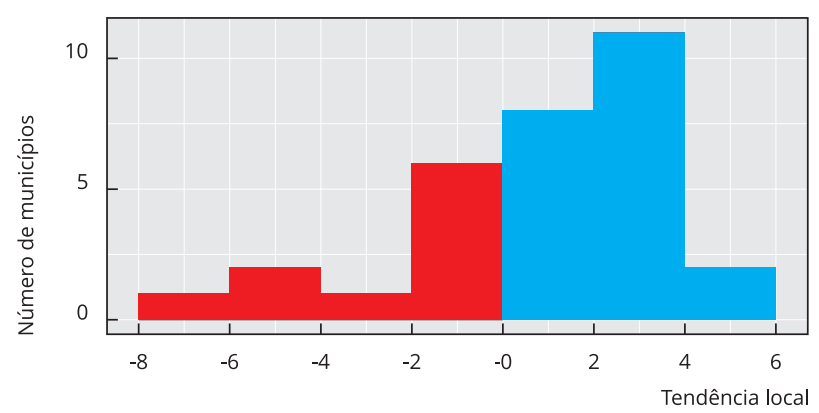

4c) Aglomerado 3

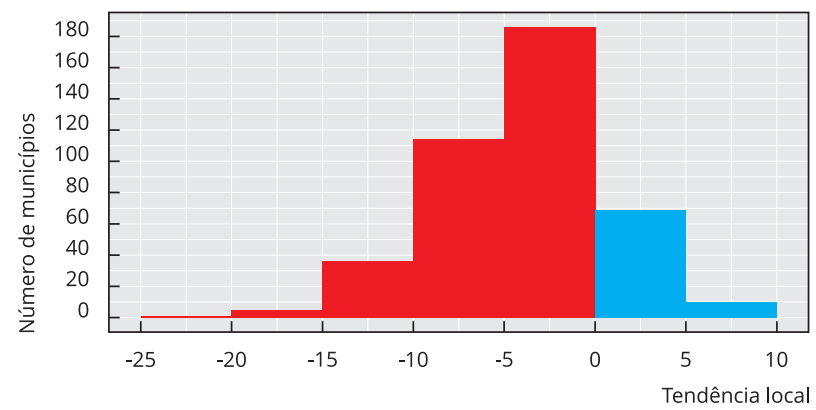

4e) Aglomerado 5

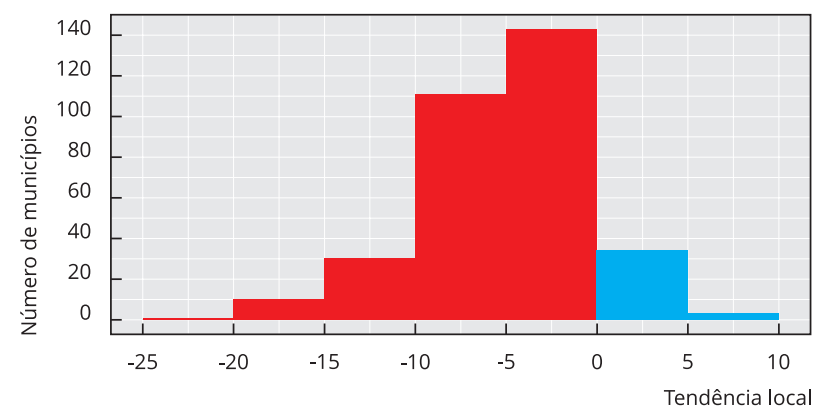

4b) Aglomerado 2

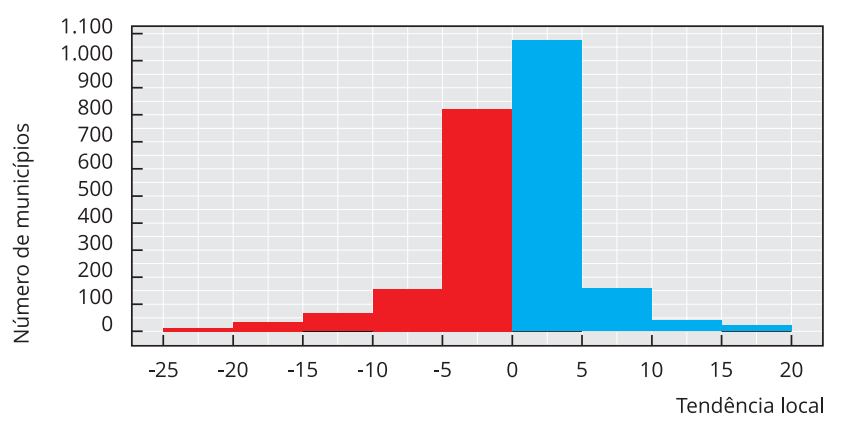

4d) Aglomerado 4

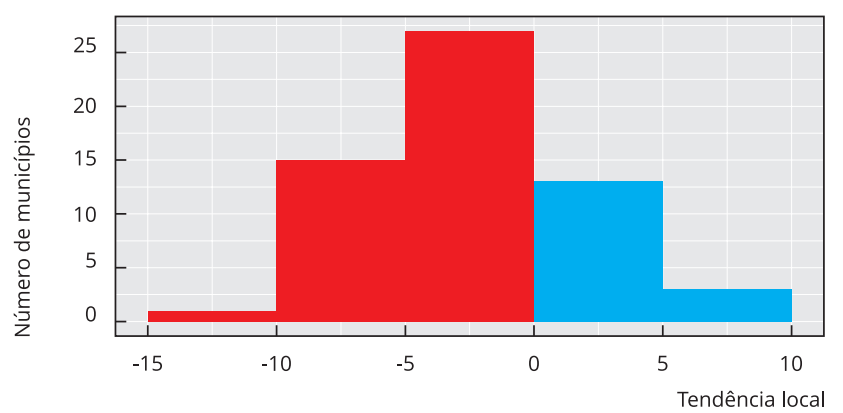

4f) Aglomerado 6

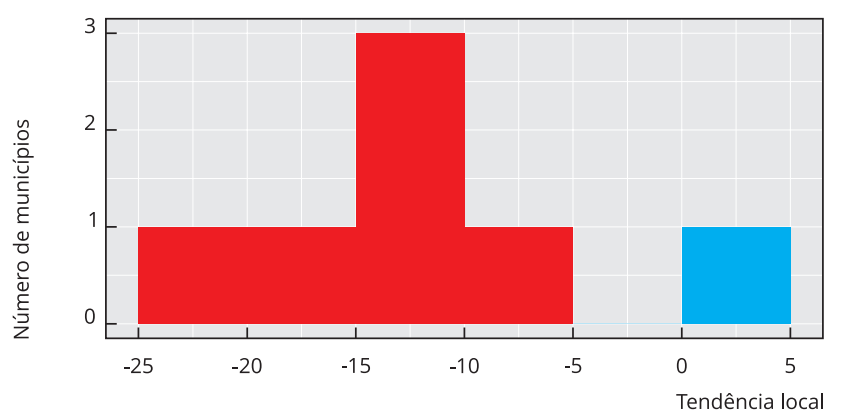

Nota: os intervalos negativos foram representados na cor vermelha, e os positivos, na cor azul. 


\section{Figura 5}

Tendência temporal local das coberturas vacinais dos municípios pertencentes aos aglomerados significativos da análise de varredura da poliomielite. Brasil, 2006-2016

5a) Aglomerado 1

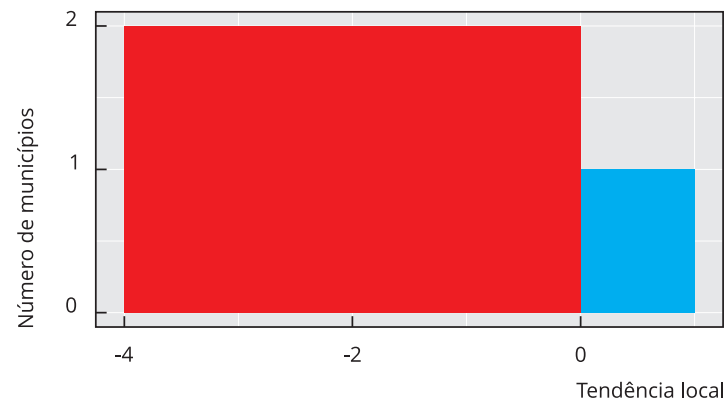

5c) Aglomerado 3

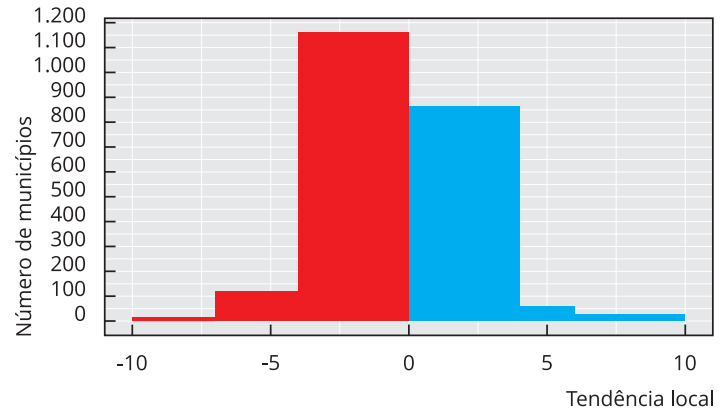

5e) Aglomerado 5

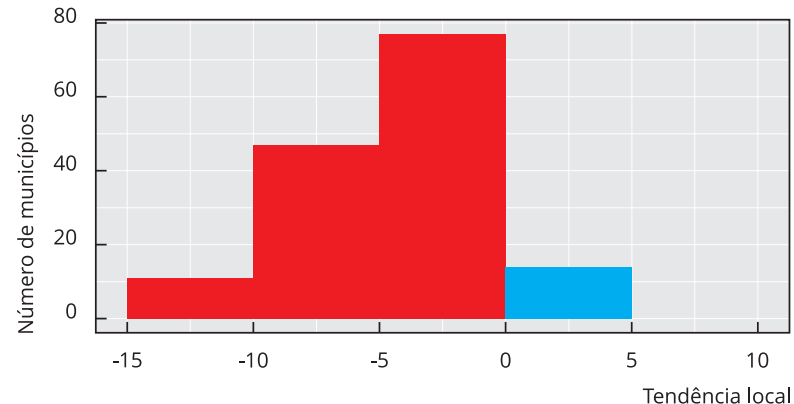

5b) Aglomerado 2

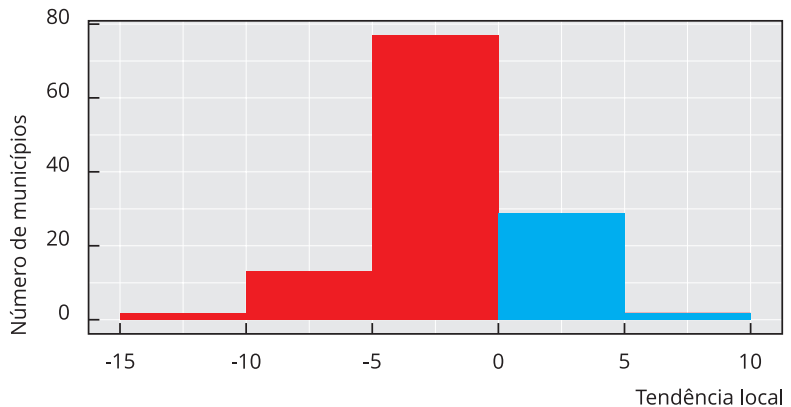

5d) Aglomerado 4

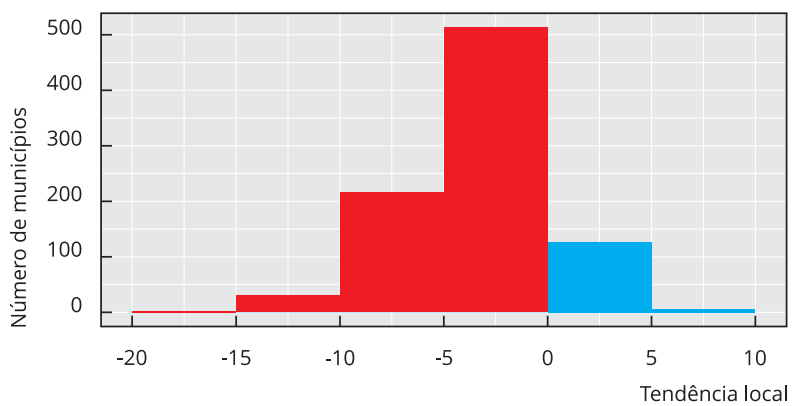

Nota: os intervalos negativos foram representados na cor vermelha, e os positivos, na cor azul. 


\section{Figura 6}

Tendência temporal local das coberturas vacinais dos municípios pertencentes aos aglomerados significativos da análise de varredura da tríplice viral. Brasil, 2006-2016.

6a) Aglomerado 1

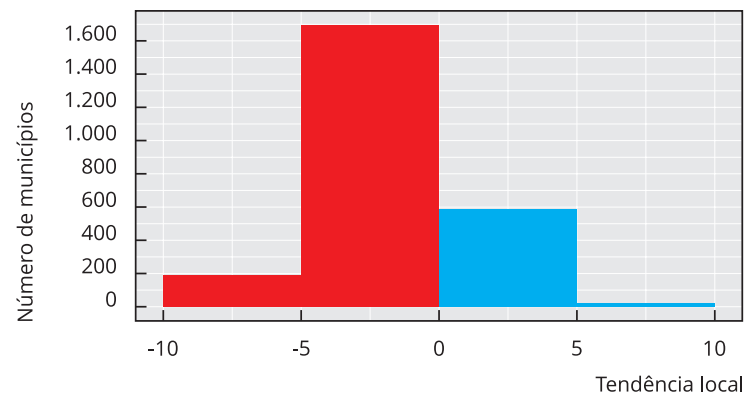

6a) Aglomerado 3

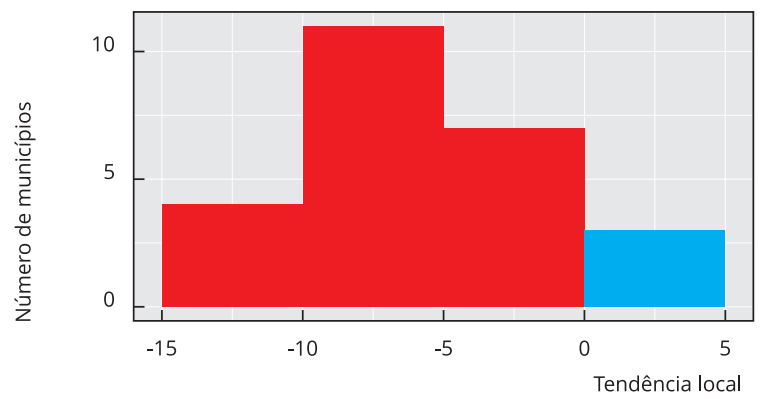

6a) Aglomerado 2

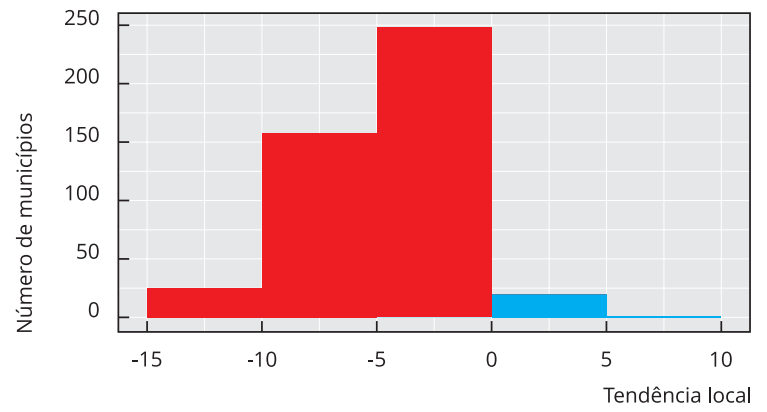

6d) Aglomerado 4

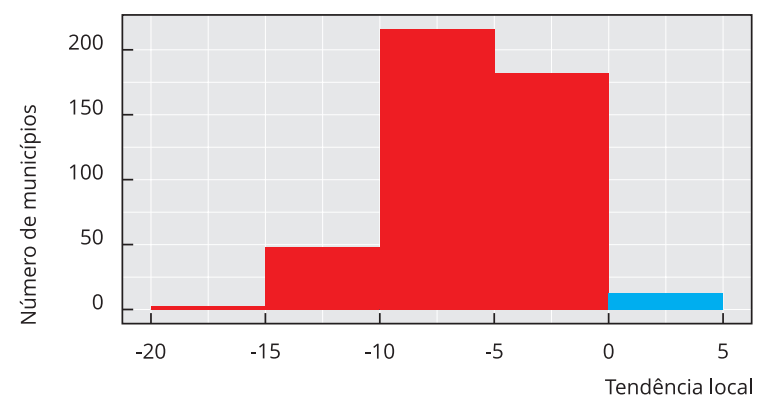

Nota: os intervalos negativos foram representados na cor vermelha, e os positivos, na cor azul.

\section{Discussão}

O estudo teve como objetivo identificar áreas com queda da cobertura vacinal de BCG, poliomielite e tríplice viral no Brasil no período de 2006 a 2016. A cobertura vacinal média no território nacional, para essas três vacinas, demonstrou o alcance das metas de $95 \%$ de cobertura para tríplice viral e poliomielite, e de $90 \%$ da cobertura da BCG, conforme estipulado pelo PNI 4. Entretanto, as análises, em nível subnacional, permitiram identificar heterogeneidades importantes entre os municípios.

A imunização é um dos elementos para o alcance da equidade em saúde, sendo essa estratégia a forma mais eficaz na prevenção das doenças imunopreveníveis e melhoria dos indicadores de saúde 15.

Identificar as regiões onde as coberturas vacinais não apresentam abrangência adequada é parte fundamental para o sucesso do PNI na saúde pública. Para isso, os sistemas de monitoramento e avaliação, por meio de Registros Informatizados de Imunização, são uma das estratégias de considerável efetividade e acessibilidade nesse papel 16. Mesmo havendo limitações acerca da integralidade e qualidade dos dados, a existência desses permite o desenvolvimento de uma vigilância dos serviços de vacinação 17 .

É importante elucidar as causas para que algumas regiões exprimissem coberturas acima de $100 \%$, podendo estar relacionado com recém-nascidos registrados em localidades distintas daquelas de residência da mãe, principalmente em municípios de pequeno porte e sem maternidades, alterando o 
denominador de nascidos vivos no cálculo de cobertura. Somado a isso, a maior facilidade de acesso às salas de vacinação por alguns usuários em municípios vizinhos, elevando o número de vacinados além da população-alvo do respectivo município, resultando igualmente em coberturas acima de $100 \% 18$.

Identificar aglomerados com menor número de vacinados por meio das tendências temporais pode auxiliar na identificação das populações com dificuldade ao acesso ou à adesão à vacinação, sendo um elemento importante para o monitoramento e a avaliação das intervenções do PNI. Dessa forma, as análises de VETT visualizaram uma tendência de redução do número de crianças vacinadas entre os anos de 2006 e 2016 em níveis subnacionais, sendo que algumas regiões podem ser consideradas muito críticas, como aquelas com TI de redução no número de vacinados maiores que as TE.

Pará, Maranhão e Bahia apresentaram decréscimo no número de vacinados mais acelerado que o restante do país para as três vacinas. Essas áreas podem ser consideradas como mais preocupantes em relação à completude do esquema vacinal das crianças de até um ano de idade para BCG, poliomielite e tríplice viral. Destaca-se, ainda, que outros estados do Norte e Nordeste também apresentaram reduções importantes no número de vacinados, como Piauí, Tocantins, Acre, Rondônia, Amapá e Amazonas.

Goiás, Mato Grosso e Minas Gerais apresentaram características similares aos estados das regiões Norte e Nordeste. Entretanto, verificou-se que esses representaram uma menor proporção entre os municípios dos aglomerados, quando comparados aos aglomerados das regiões Norte e Nordeste.

As análises apontam ainda regiões com tendências de redução anual no número de vacinados com uma queda menor do restante do país, como aglomerados do Sul, Sudeste e Centro-oeste. Em relação ao aumento de vacinados ao ano, verificou-se essa tendência apenas nos aglomerados do oeste do Mato Grosso e na região do Distrito Federal.

Esses resultados concordam com as evidências mostradas por Braz et al. ${ }^{19}$, em que foram analisadas as coberturas vacinais de dez vacinas pertencentes ao calendário vacinal nacional, os estados do Norte e Nordeste foram classificados como os de maior risco para a transmissão das doenças imunopreveníveis, exatamente pelas baixas coberturas vacinais nos estados dessas regiões.

Estudos realizados em distintos locais do país apontaram diferenças na cobertura para grupos sociais 20,21, análises em Salvador (Bahia) e no Maranhão apontaram achados importantes: a heterogeneidade entre os estratos socioeconômicos, com coberturas mais baixas em estratos de crianças em situação de vulnerabilidade face às doenças infecciosas, tendo em vista suas condições de vida 22 . Condições sociodemográficas, como baixa renda familiar, baixa escolaridade dos responsáveis, número elevado de filhos por mãe e ordem de nascimento das crianças, foram relacionadas com a não vacinação $23,24,25$.

Observando os resultados da Síntese de Indicadores Sociais, oriundos dos dados da Pesquisa Nacional por Amostra de Domicílios, é possível verificar que o Norte e o Nordeste do país apresentaram menores valores de renda mensal domiciliar per capita média em todo o Brasil. Somado a isso, está a maior desigualdade social vivenciada nessas regiões, em que aproximadamente $30 \%$ dos residentes do Norte e Nordeste sofrem com restrições de acesso a, no mínimo, três das cinco principais dimensões analisadas, sendo elas: educação, serviços de saneamento básico, proteção social, condições de moradia e comunicação 26 . Esses resultados concordam com evidências do Inquérito de Cobertura Vacinal, em que as menores coberturas podem ser um resultado das piores condições socioeconômicas vivenciadas 27 . Dessa forma, as tendências temporais de reduções no número de vacinados encontrados nas análises de VETT podem estar relacionadas a essas características regionais.

Ademais, é necessário criar estratégias para envolver a população nas ações de imunizações, propiciando informação, conhecimento, empoderamento dos indivíduos, reduzindo barreiras culturais e problemas relacionados à desinformação sobre a vacinação 28 . A literatura evidencia que dificuldades no acesso aos serviços de saúde interferem na vacinação, destacando-se: distância entre residência e serviços de saúde, dificuldades de acesso ao transporte público, horário de funcionamento das unidades de saúde restrito, deficiência na educação permanente dos profissionais de saúde e número excessivo de pessoas adscritas no território 22,29,30.

De acordo com Ryman et al. 31, a adoção de práticas de gestão inovadoras, com incentivo à vacinação e o monitoramento da cobertura mediante a realização de inquéritos domiciliares de forma periódica, deve ir ao encontro das estratégias propostas pela OMS, com ampliação da oferta mais pró- 
xima às comunidades, disseminação das informações, promoção da saúde e ações de orientação em visitas domiciliares utilizando, como recurso, os Agentes Comunitários de Saúde no fortalecimento de relações acolhedoras e articulação entre profissionais de saúde e populações.

Outro elemento importante é a disponibilidade de imunobiológicos nas salas de vacina. O desabastecimento de vacinas ainda é comum no Brasil, sendo que existem diversos documentos legais como inquéritos civis instaurados e notas informativas, que retratam a questão de insuficiência de recursos, bem como dependência da capacidade produtiva dos laboratórios das entregas internacionais e dos trâmites alfandegários 32. Em 2015 e 2017, a Sociedade Brasileira de Imunizações 33 e o Ministério da Saúde 34 publicaram notas informativas sobre o desabastecimento da vacina BCG, demonstrando a dificuldade que o país possui em garantir os insumos necessários para vacinação. A falta do imunobiológico, como no caso da BCG, pode resultar na não vacinação oportuna, o que pode ter impactado, de forma tardia, na redução de vacinados em 2016 no Brasil.

Importante destacar que, desde 1998, estimou-se 350 mil casos de poliomielite no mundo, a OMS, por meio da Global Polio Eradication, concentrou esforços para erradicação da doença, tanto pelo poliovírus selvagem como pelo poliovírus derivado da vacina. Como resultados dos esforços globais, o número de casos de poliomielite selvagem diminuiu em 99\%, levando a 406 casos em 201335.

Globalmente, apesar de muitos países terem eliminado a poliomielite, alguns permanecem endêmicos, como Afeganistão, Paquistão e Nigéria. Em contrapartida, outros locais estão experimentando a reintrodução do poliovírus, como Guiné Equatorial, Etiópia, Somália, Camarões, Iraque e Síria, dificultando os esforços de erradicação da poliomielite 36 .

Ressalta-se que, enquanto houver infectados com a poliomielite, outras crianças de diferentes países estão em risco de contrair a doença. Segundo a OMS, o fracasso de erradicar a poliomielite nesses países pode resultar em 200 mil casos novos por ano 37.

No Brasil, dados do Ministério da Saúde indicam que a proporção de crianças brasileiras imunizadas em 2017 contra a poliomielite é a mais baixa desde 2000, sendo ainda estimadas que apenas $77 \%$ receberam as três doses preconizadas no primeiro ano de vida (http://tabnet.datasus.gov.br/cgi/ tabcgi.exe?pni/cnv/cpniuf.def, acessado em 18/Dez/2018).

A Organização Pan-Americana da Saúde (OPAS) emitiu uma nota de alerta sobre a importância da implementação de ações para aumentar a cobertura da vacinação contra a poliomielite para 95\%, essa medida tem como finalidade reverter a diminuição da cobertura vacinal contra a poliomielite que vem ocorrendo em países da América, incluindo o Brasil 38.

Especificamente sobre o sarampo, no período de 1968 a 1991, o país enfrentou nove epidemias dessa doença, com média de uma epidemia ao ano 39. A partir de 1992, com a implantação do Plano de Controle e Eliminação do Sarampo, ocorreu intensificação das ações de vigilância epidemiológica e campanhas de vacinação em massa, possibilitando uma acentuada queda na incidência da doença 40 .

A partir dos anos 2000, ocorreram alguns surtos de sarampo de importância epidemiológica no sertão da Bahia (2006), na Paraíba (2010), em Pernambuco (2013/2014) e no Ceará (2013 a 2015), este último registrando 1.052 casos da doença 41 . Após sucessivas ações de vigilância e imunizações, em 2016, o Brasil recebeu o certificado de eliminação da circulação do vírus do sarampo pela OMS, declarando a região das Américas livre do sarampo 39.

Desde janeiro de 2018, foram verificados surtos de sarampo nos estados de Roraima e Amazonas, contabilizando, até o mês de junho de 2018, 314 casos 39. O surto de sarampo ocorrido no Brasil evidencia as consequências da redução do número de vacinados, que vem ocorrendo anualmente no país. A taxa de cobertura da tríplice viral, que alcançava $96 \%$ das crianças em 2015 , baixou para $84 \%$ em 2017 e possibilitou o retorno da infecção no país (http://tabnet.datasus.gov.br/cgi/tabcgi.exe?pni/ cnv/cpniuf.def, acessado em 18/Dez/2018).

Os resultados dos aglomerados citados anteriormente são analisados a partir de uma tendência temporal média de todos os municípios pertencentes a esses aglomerados espaciais. Essa abordagem facilita a compreensão das regiões com padrões temporais distintos em relação a todo o território nacional, mas pode anular heterogeneidades existentes entre os municípios de um determinando aglomerado. Dessa forma, observar as diferenças no interior dessas áreas também é importante para compreender as tendências locais de vacinação e demonstrar que essas reduções podem ser sentidas de forma singular para cada município. Essa evidência aumenta ainda mais a importância de substi- 
tuir a elaboração de planos de ações vacinais, a partir da demanda espontânea dos usuários, por um planejamento das ações, da gestão dos serviços e da operacionalização das ações de imunização a partir do monitoramento do estado vacinal das pessoas em cada um dos municípios 42 .

Mesmo em países com sistemas de saúde bem estabelecidos e com programas de imunização efetivos, os avanços alcançados em anos anteriores podem ser perdidos facilmente. Sem constante monitoramento, sistemas de imunização podem deteriorar-se, tendo como consequência a redução no número de vacinados, principalmente quando os países passam por perturbações políticas e econômicas 42, como no caso do Brasil. O acesso à imunização deve ser universal, independentemente de sua localização geográfica, assim é importante que políticas e programas realizem medidas inovadoras e mais efetivas para a redução das iniquidades na vacinação 43 .

Importante destacar que o estudo apresenta limitações acerca da própria fonte de dados secundários utilizada, pois, atualmente, existem duas modalidades de coleta das informações de cobertura vacinal pelos sistemas de informação no Brasil: o primeiro é mais recente, datando de 2013, em que os dados são transmitidos on-line e em tempo real; e o anterior, em que o registro das vacinas aplicadas são realizadas off-line, e os dados são enviados mensalmente para o DATASUS.

Ambos os sistemas possuem limitações, sendo que o primeiro necessita de atualizações constantes de seu sistema pelas salas de vacina, e o segundo carece do envio dessas informações pelos responsáveis em cada município, o que pode acarretar uma não fidedignidade dos dados 44 . Em consequência, é possível que exista uma diferença entre os dados locais e os números consolidados em nível nacional, requerendo atenção e esclarecimento mais detalhado entre os municípios acerca dos resultados apresentados nessa investigação.

Outra limitação também está relacionada aos dados de cobertura vacinal presentes no SAPI, pois como esse é realizado por meio do número de doses aplicadas, no caso das vacinas de múltiplas doses, como poliomielite, pode haver diversos problemas relacionados à confiabilidade dos dados presentes nos sistemas de informação e na coleta de dados 21 . A disponibilidade parcial dos dados de doses aplicadas na rede privada e a falta de informações de vacinados em dias de campanhas nacionais também podem interferir nos resultados apresentados. Ademais, como foi supracitado, conhecer a população-alvo para as vacinas analisadas por meio do SINASC pode não representar o número real de crianças de até um ano de idade por municípios brasileiros. Ressalta-se que o Sistema de Informação do Programa Nacional de Imunização (SIPNI), implementado a partir de 2010, pode aprimorar a qualidade dessas informações, haja vista que o sistema utiliza informações nominais dos indivíduos vacinados.

Em suma, o estudo apresenta evidências de uma importante redução na cobertura vacinal da BCG, poliomielite e tríplice viral nos últimos anos e identifica heterogeneidades espaciais dessa queda nas diferentes regiões do país. Assim, constata-se que as imunizações no país variam consideravelmente entre os municípios brasileiros, demandando planejamento estratégico condizente com as características de cada localidade, consolidação de tecnologias organizacionais para serviços de saúde e capacidades ampliadas de humanização para acolher as demandas da população e evitar oportunidades perdidas de vacinação. Essas medidas podem contribuir tanto para o controle da redução de cobertura vacinal como para o reaparecimento de doenças no Brasil. Adicionalmente, são necessários novos estudos acerca da temática no objetivo de compreender fatores associados a essas quedas de cobertura vacinal. 


\section{Colaboradores}

L. H. Arroyo, A. C. V. Ramos, M. Yamamura, J. A. Crispim, D. Cartagena-Ramos, M. Fuentealba-Torres e D. T. Santos contribuíram com a concepção, análise e interpretação dos dados, redação do artigo e aprovação final da versão a ser publicada. T. H. Weiller e P. F. Palha contribuíram com a revisão crítica relevante do conteúdo intelectual e aprovação final da versão a ser publicada. R. A. Arcêncio contribuiu com a concepção, análise e interpretação dos dados, revisão crítica relevante do conteúdo intelectual e aprovação final da versão a ser publicada.

\section{Informações adicionais}

ORCID: Luiz Henrique Arroyo (0000-0003-33020502); Antônio Carlos Vieira Ramos (0000-00031536-1768); Mellina Yamamura (0000-00015228-8788); Teresinha Heck Weiller (0000-00032531-0155); Juliane de Almeida Crispim (00000003-4642-9075); Denisse Cartagena-Ramos (0000-0002-8828-2190); Miguel Fuentealba-Torres (0000-0003-4343-6341); Danielle Talita dos Santos (0000-0001-9817-7979); Pedro Fredemir Palha (0000-0002-5220-4529); Ricardo Alexandre Arcêncio (0000-0003-4792-8714).

\section{Agradecimentos}

Agradecemos à Profa. Dra. Valeria Conceição de Oliveira da Universidade Federal de São João del-Rei pelo apoio nos aspectos conceituais durante a elaboração do estudo. À Fundação de Amparo à Pesquisa do Estado de São Paulo (FAPESP) pelo fomento à presente pesquisa científica.

\section{Referências}

1. Ozawa S, Mirelman A, Stack ML, Walker DG, Levine OS. Cost-effectiveness and economic benefits of vaccines in low- and middle-income countries: a systematic review. Vaccine 2012; 31:96-108.

2. Andre FE, Booy R, Bock HL, Clemens J, Datta SK, John TJ, et al. Vaccination greatly reduces disease, disability, death and inequity worldwide. Bull World Health Organ 2008; 86:140-6.

3. World Health Organization. Global vaccine action plan 2011-2020. Geneva: World Health Organization; 2013.

4. Ministério da Saúde. Programa Nacional de Imunizações. Coberturas vacinais no Brasil. Período: 2010-2014. http://portalarquivos2. saude.gov.br/images/pdf/2017/agosto/17/ AACOBERTURAS-VACINAIS-NO-BRA SIL---2010-2014.pdf (acessado em 18/ Dez/2018).

5. Santos GRD, Silva SS, Guimarães EAA, Cavalcante RB, Oliveira VC. Avaliação do monitoramento rápido de coberturas vacinais na Região Ampliada de Saúde Oeste de Minas Gerais, 2012. Epidemiol Serv Saúde 2016; 25:55-64.

6. Ministério da Saúde. Calendário Nacional de Vacinação. http://portalms.saude.gov.br/sau de-de-a-z/vacinacao/calendario-vacinacao (acessado em 30/Abr/2019).

7. Olive JK, Hotez PJ, Damania A, Nolan MS. The state of the antivaccine movement in the United States: a focused examination of nonmedical exemptions in states and counties. PLoS Med 2018; 15:e1002578.

8. Barata RB, Sampaio de Almeida Ribeiro MC, de Moraes JC, Flannery B; Vaccine Coverage Survey 2007 Group. Socioeconomic inequalities and vaccination coverage: results of an immunisation coverage survey in 27 Brazilian capitals, 2007-2008. J Epidemiol Community Health 2012; 66:934-41.

9. Domingues CMAS, Teixeira AMS. Coberturas vacinais e doenças imunopreveníveis no Brasil no período 1982-2012: avanços e desafios do Programa Nacional de Imunizações. Epidemiol Serv Saúde 2013; 22:9-27.

10. Moraes JC, Ribeiro MCSA. Desigualdades sociais e cobertura vacinal: uso de inquéritos domiciliares. Rev Bras Epidemiol 2008; 11 Suppl 1:113-24.

11. Kulldorff M, Nagarwalla N. Spatial disease clusters: detection and inference. Stat Med 1995; 14:799-810.

12. Lawson AB. Bayesian disease mapping: hierarchical modeling in spatial epidemiology. 3 rd Ed. New York: CRC Press; 2018.

13. Moraga P, Kulldorff M. Detection of spatial variations in temporal trends with a quadratic function. Stat Methods Med Res 2016; 25:1422-37. 
14. Kulldorff M. SaTScan user guide: for version 9.6. https://www.satscan.org/cgi-bin/ satscan/register.pl/SaTScan_Users_Guide. pdf?todo=process_userguide_download (acessado em 18/Dez/2018).

15. United Nations Children Fund; World Health Organization. Global immunization vision and strategy. http://www.who.int/vaccinesdocuments/ (acessado em 18/Dez/2018).

16. Cutts FT, Claquin P, Danovaro-Holliday MC, Rhoda DA. Monitoring vaccination coverage: defining the role of surveys. Vaccine 2016; 34:4103-9.

17. Luhm KR, Waldman EA. Sistemas informatizados de registro de imunização: uma revisão com enfoque na saúde infantil. Epidemiol Serv Saúde 2009; 18:65-78.

18. Bueno MM, Matijasevich A. Avaliação da cobertura vacinal contra hepatite B nos menores de 20 anos em municípios do Estado do Rio Grande do Sul, Brasil. Epidemiol Serv Saúde 2011; 20:345-54.

19. Braz RM, Domingues CMAS, Teixeira AMS, Luna EJA, Braz RM, Domingues CMAS, et al. Classificação de risco de transmissão de doenças imunopreveníveis a partir de indicadores de coberturas vacinais nos municípios brasileiros. Epidemiol Serv Saúde 2016; 25:745-54.

20. Moraes JC, Barata RCB, Ribeiro MCSA, Castro PC. Cobertura vacinal no primeiro ano de vida em quatro cidades do Estado de São Paulo, Brasil. Rev Panam Salud Pública 2000; 8:332-41.

21. Moraes JC, Ribeiro MCSA. Desigualdades sociais e cobertura vacinal: uso de inquéritos domiciliares. Rev Bras Epidemiol 2008; 11 Suppl 1:113-24.

22. Barata RB, Pereira SM. Desigualdades sociais e cobertura vacinal na cidade de Salvador, Bahia. Rev Bras Epidemiol 2013; 16:266-77.

23. Silva AAM, Gomes UA, Tonial SR, Silva RA. Cobertura vacinal e fatores de risco associados à não vacinação em localidade urbana do Nordeste brasileiro, 1994. Rev Saúde Pública 1999; 33:147-56.

24. Tertuliano GC, Stein AT. Atraso vacinal e seus determinantes: um estudo em localidade atendida pela Estratégia Saúde da Família. Ciênc Saúde Colet 2011; 16:523-30.

25. Nunes DM, Menezes FC, Igansi CN, Araújo WN, Segatto TCV, Costa KCC, et al. Inquérito da cobertura vacinal de tríplice bacteriana e tríplice viral e fatores associados à não vacinação em Santa Maria, Distrito Federal, Brasil, 2012. Rev Pan-Amazônica Saúde 2018; 9:9-17.

26. Instituto Brasileiro de Geografia e Estatística. Síntese de indicadores sociais: uma análise das condições de vida da população brasileira: 2018. Rio de Janeiro: Instituto Brasileiro de Geografia e Estatística; 2018.
27. Centro de Estudos Augusto Leopoldo Ayrosa Galvão. Inquérito de cobertura vacinal nas áreas urbanas das capitais. Brasil (cobertura vacinal 2007). http://bvsms.saude.gov.br/bvs/ publicacoes/inquerito_cobertura_vacinal_ur banas.pdf (acessado em 30/Abr/2019).

28. Succi RCM. Vaccine refusal - what we need to know. J Pediatr (Rio J.) 2018; 94:574-81.

29. Ferreira AV, Freitas PHB, Viegas SMDF, Oliveira VC. Acesso à sala de vacinas da Estratégia Saúde da Família: aspectos organizacionais. Rev Enferm UFPE on line 2017; 11:3869-77.

30. Duarte DC, Oliveira VC, Guimarães EAA, Viegas SMF. Vaccination access in primary care from the user's perspective: senses and feelings about healthcare services. Esc Anna Nery Rev Enferm 2019; 23:e20180250.

31. Ryman TK, Dietz V, Cairns KL. Too little but not too late: results of a literature review to improve routine immunization programs in developing countries. BMC Health Serv Res 2008; 8:134

32. Ministério Público Federal dos Direitos do Cidadão. Desabastecimento de vacinas fornecidas pela União. http://www.mpf.mp.br/regiao3/ atuacao/direitos-do-cidadao/naop-atas-desessoes-e-votos/naop-atas-de-sessoes-e-vo tos-2017/21-06-2017-ata-109a-e-votos9/vo to-no-4-626-2017-naop-pfdc-prr3aregiao-re ferencia-ic-1-21-000-002137-2015-16/at_do wnload/file (acessado em 30/Abr/2019).

33. Sociedade Brasileira de Imunizações. Nota Técnica 17/11/2015. Desabastecimento das vacinas. http://www.sbim.org.br (acessado em 30/Abr/2019).

34. Ministério da Saúde. Nota Informativa no 17. Informa acerca da situação da distribuição de imunobiológicos na rotina. http://www. mt.gov.br/documents/21013/5691628/No ta+do+Ministério+da+Saúde/dbebb981-0f184fe8-9501-a574f46558ed (acessado em 30/ Abr/2019).

35. Falleiros-Arlant LH, Avila-Agüero ML, Brea del Castillo J, Marino C. El desafío del cambio de la vacuna inactivada contra poliomielitis en América Latina: Declaración de la Sociedad Latinoamericana de Infectología Pediátrica (SLIPE). Rev Chil Infectol 2014; 31:590-6.

36. Global Polio Eradication Initiative. Key at-risk countries. http://polioeradication.org/wherewe-work/key-at-risk-countries/ (acessado em 18/Dez/2018).

37. World Health Organization. Poliomyelitis. https://www.who.int/en/news-room/factsheets/detail/poliomyelitis (acessado em 18/ Dez/2018). 
38. Organização Pan-Americana da Saúde. Países das Américas devem tomar medidas para manter a pólio fora da Região. https://www.paho. org/bra/index.php?option=com_content\& view $=$ article \&id $=5789$ : paises - das-americas devem-tomar-medidas-para-manter-a-poliofora-da-regiao\&Itemid=820 (acessado em 18/ Dez/2018).

39. Ministério da Saúde. Informe técnico da campanha de seguimento contra o sarampo. http:// sipni.datasus.gov.br (acessado em 18/Dez/ 2018).

40. Departamento de Vigilância Epidemiológica, Secretaria de de Vigilância em Saúde, Ministério da Saúde. Programa Nacional de Imunizações (PNI): 40 anos. Brasília: Ministério da Saúde; 2013.

41. Moura ADA, Braga AVL, Carneiro AKB, Alves ECS, Bastos CMM, Nunes IH, et al. Monitoramento rápido de vacinação na prevenção do sarampo no Estado do Ceará, em 2015. Epidemiol Serv Saúde 2018; 27:e2016380.
42. Silva BS, Coelho HV, Cavalcante RB, Oliveira VC, Guimarães EAA, Silva BS, et al. Evaluation study of the National Immunization Program Information System. Rev Bras Enferm 2018; 71 Suppl 1:615-24.

43. World Health Organization. 2018 Assessment Report of the Global Vaccine Action Plan: Strategic Advisory Group of Experts on Immunization. https://www.who.int/im munization/global_vaccine_action_plan/ SAGE_GVAP_Assessment_Report_2018_ EN.pdf?ua=1\&usg=AOvVaw3QyWH_zK3GCe-pPt4FEi7G (acessado em 30/Abr/2019).

44. Ministério da Saúde. Programa Nacional de Imunizações. Nota Informativa no 47/2018. https://sei.saude.gov.br/sei/controlador. php? acao=documento_imprimir_web\&a cao_origem $=$ arvore_visualizar\&id_documen to $=3228945 \&$ infra_sist...2/5 (acessado em 21/ Dez/2018). 


\section{Abstract}

Immunization is known to be one of the most successful and cost-effective health interventions, resulting in the eradication and control of various diseases in the world. However, Brazil has experienced a worrisome drop in vaccination coverage, associated with the resurgence of various previously controlled or eradicated diseases. This study thus conducted a situational diagnosis weighing Brazil's different regions and time trends in vaccination coverage in order to identify areas with reduction in vaccination coverage for BCG, poliomyelitis, and MMR. This ecological study collected data on the number of children up to one year of age who had been vaccinated with these three vaccines from 2006 to 2016, according to municipality (county). Data were obtained from the Brazilian Health Informatics Department. A spatial scan was performed, analyzing spatial variations in the time trends for vaccination coverage. Downward trends were seen in the number of immunizations in Brazil, with reductions of 0.9\%, 1.3\%, and 2.7\% per year for BCG, poliomyelitis, and $M M R$, respectively. Significant decreases were also seen in all five major geographic regions with time trends in the reduction of vaccination coverage. The study evidenced an important reduction in vaccination coverage in recent years, with major heterogeneity between municipalities. Thus, focused attention and strategic planning in keeping with each local area's characteristics are necessary to address both the reduction of vaccination coverage and the resurgence of vaccine-preventable diseases in Brazil.

Vaccination Coverage; Immunization; Spatial Analysis

\section{Resumen}

La inmunización está reconocida como una de las intervenciones más exitosas y costo-eficientes, consiguiendo la erradicación y control de diversas enfermedades en todo el mundo. Sin embargo, se ha observado una preocupante reducción en la cobertura de la vacunación en Brasil, conllevando el recrudecimiento de algunas enfermedades hasta entonces superadas. De esta forma, con el fin de realizar un diagnóstico situacional, que pondere las diferentes regiones del país y la tendencia temporal de cobertura vacunación, el presente estudio tuvo como objetivo evidenciar áreas con una caída de la cobertura vacunación respecto a $B C G$, poliomielitis y triple vírica en Brasil. Se trata de un estudio ecológico, que recabó información acerca del número de niños de hasta un año de edad inmunizados con estas tres vacunas, durante el período entre 2006 y 2016, por municipios brasileños. Los datos se consiguieron a través del Departamento de Informática del SUS. Se realizó un barrido espacial, analizando las variaciones espaciales en las tendencias temporales de cobertura de vacunación. Se observó una tendencia de reducción en el número de inmunizaciones en Brasil, con caídas de 0,9\%, 1,3\% y 2,7\% al año, en el caso de $B C G$, poliomielitis y triple vírica, respectivamente. Además, se verificaron aglomerados significativos con tendencias temporales de reducción en la cobertura de vacunación dentro de las cinco regiones brasileñas. El estudio evidencia una importante reducción en la cobertura de vacunación durante los últimos años, constatando heterogeneidades considerables entre los municipios. De esta forma, una atención singular y planificación estratégica, acorde con las características de cada localidad, son necesarias para el control, tanto de la reducción de la cobertura de vacunación, como del resurgimiento de enfermedades en Brasil.

Cobertura de Vacunación; Inmunización; Análisis Espacial
Recebido em 24/Jan/2019

Versão final reapresentada em 17/Set/2019 Aprovado em 23/Set/2019 